\section{8d CHALLENGES IN DIAGNOSIS AND PREVENTION OF OCCUPATIONAL RESPIRATORY DISEASES}

JH Rantanen. University of Helsinki, Department of Public Health/Occupational Health, Helsinki, Finland

\subsection{6/oemed-2018-ICOHabstracts.654}

Occupational respiratory diseases (ORDs) constitute one of the most prevalent groups of occupational diseases (ODs) with a multitude of diagnoses (pneumoconioses, other fibroses, infectious diseases, airway diseases such as asthma and COPD, other hypersensitivities and irritations, and most importantly, cancers. In addition to acute or subacute outcomes, ORDs may result from cumulative exposures during years or decades and in cancers latency periods of up to 50 years may occur. They often have a progressive course with severely disabling or fatal outcome. Their diagnosis is highly demanding and need multiprofessional, multidisciplinary teamwork, such as occupational medicine, pulmonology, occupational hygiene, clinical physiology, and also well-established clinical facilities with advanced laboratory and imaging resources.

The diagnostic process follows the generic logic of diagnosis of ODs, including early monitoring of exposures (workplace surveillance), observation of subclinical findings of groups at risk, early notification of symptoms (workers' health surveillance), careful examination of work and exposure history (occupational hygiene and anamnesis), clinical investigation (physical, clinical studies, laboratory analyses, imaging, possible functional testing and follow-up at work and possible provocation tests, e.g. in asthma). In cases of cancers with long latencies, the health surveillance needs to be extended upon the retirement age and beyond.

In good occupational health practice, the process does not end with the diagnosis. In addition to proper treatment, a thorough statement, based on acquired evidence of the diagnosed outcome is needed for legal and insurance purposes. Rehabilitation measures may be needed. The notification to the authorities and OD registries will be made. In many countries, the examination of the workplace and feedback for prevention of further cases is obligatory. Severe and fatal cases of ODs lead e.g. in Finland to police investigation.

For adequate preventive measures, structural, primary, secondary and tertiary prevention are needed and the earliest possible identification of disease is emphasised.

\section{8e CHALLENGES IN DIAGNOSIS AND PREVENTION OF OCCUPATIONAL SKIN DISEASES}

SM John. Dept. Dermatology, Environmental Medicine, Health Theory, University of Osnabrueck, Germany

\subsection{6/oemed-2018-ICOHabstracts.655}

Work-related skin diseases (WRSD) are at the top of all notified occupational diseases with a share of more than $40 \%$ in some European countries. For example, currently, in Germany, about $30 \%$ of annual notifications fall on irritant or allergic contact dermatitis, another $10 \%$ on certain forms of occupational nonmelanoma skin cancer by solar UV radiation exposure at the workplace. For WR contact dermatitis (ILO-list: 2.2.1 and 2.2.2), it can be stated that targeted prevention strategies have shown to be highly effective in notified cases, however, the reach out to affected workers is still limited in many countries due to underreporting. Prevention measures include improved workers' education, specific barrier-recovery oriented skin care methods, better use of protective equipment, selection of safer products, and early medical intervention. Recently, required minimum standards for WRSD prevention, postulating the above mentioned concepts in an interlocking preventive system, have recently been published in Europe. Regarding WR skin cancer in outdoor workers a similar efficacy of organisational measures, workers' education, and suitable protective equipment based prevention measures is to be expected; again, such preventive measures would be similarly easy and comparatively cheap to implement. However, in occupational skin cancer, even more so than with WR contact dermatitis, preventive measures are neglected. Furthermore, occupational skin cancer by solar UV radiation exposure at the workplace is not yet recognised as an occupational disease in many countries, contributing amongst other factors largely to the gross underreporting, and, thus, lack of preventive intervention.

UV radiation has been clearly identified as carcinogenic to humans by the International Agency for Research on Cancer (IARC), even fulfilling group I definitions for complete carcinogens, like eg Plutonium and Arsenic. The more it is astounding, that there is yet no clear work protection regulation for outdoor workers on the level of the EU; so far work protection does only comprise artificial UVR sources. The ILO list of occupational diseases includes multiple reference to occupational cancers and occupational diseases by physical radiation. The ILO Guidance Notes on Diagnostic and Exposure Criteria for Occupational Diseases will describe this specific occupational risk in outdoor workers. This will be an important step to meet the yet unmet challenge of nonmelanoma skin cancer to occupational medicine, considering that it is by far the most frequent and by incidence and prevalence fastest growing occupational malignancy.

\section{$1658 f$ DIAGNOSIS, PREVENTION AND COMPENSATION OF OCCUPATIONAL DISEASES IN THE RUSSIAN FEDERATION}

I Bukhtiyarov. FSBSI 'Izmerov Research Institute of Occupational Health', Moscow, Russia

\subsection{6/oemed-2018-ICOHabstracts.656}

In the countries of EU simultaneously act several lists of occupational diseases (OD) (opened, closed, closed regulated). National list of OD in the Russian Federation (RF) is opened type. In common RF OD list is harmonised with ILO OD list (revised 2010) with some exceptions. For example, National OD list does not recognise work related diseases.

The dynamics of the number of cases of OD in the RF in 2011-2015 and OD level (per 100 thousand people) and their trends for 2016-2030 were studied compared to the level of OD in the EU countries-27. In 2011 the number of new cases of OD was 8923 (the population were 142.9 million people); in 2015 г. the number of detected cases of occupational diseases was 7410 (the population were 146.3 million people). The level of OD was decreased from 6.24 (2011) up to 5.06 (2015) per 100 thousand people. The analysis of OD level shows that the number of detected cases of OD for the first time in the RF was significant (7-8 times) lower than in UN countries-27-40.07 per 100 thousand population (2014). 